\title{
Managing social media use:
}

\section{Whither Social Media Guidelines in News Organizations?}

\author{
MICHAËL OPGENHAFFEN, LEEN D’HAENENS, UNIVERSITY OF LEUVEN, \\ BELGIUM
}

International Journal on Media Management, Volume 17, Issue 4, pages 201-216

(Postprint version - Publisher's version available at:

http://www.tandfonline.com/doi/full/10.1080/14241277.2015.1107570)

Please contact michael.opgenhaffen@soc.kuleuven.be

INTRODUCTION

If a dude at your Super Bowl party is hyped about David Beckham's H\&M underwear ad, smack the ish out of him! \#superbowl

During the hugely popular annual Super Bowl championship game, the tweet above was posted by CNN reporter Roland Martin (@rolandsmartin) on 5 February 2012, referencing to an underwear commercial featuring David Beckham. The uproar he received in response was immediate. Accused of homophobia, the journalist insisted he had only been joking. A few weeks later, however, he stated he was leaving the news channel; in all probability due to the commotion he'd started. 
A mere 120-character tweet, probably meant as a joke, caused serious consequences both for Martin and the broadcaster he was working for. Plenty of examples exist of journalists who overstep the boundaries on social media and end up involving their employer in a downwards spiral. This specific incident's impact shouldn't be exaggerated, however, nor should, by extension, any negative consequences of social media use. Social media such as Twitter, Facebook, Instagram, or Snapchat have great appeal vis-à-vis traditional media as they provide a direct link with the public and can be used for research purposes or as an additional publication platform. But the more powerful the tool, the greater the danger. Journalists need to learn to take advantage of social media while avoiding associated hazards—possibly based on formal standards: a social media policy for journalists.

This paper discusses the difficult relationship between traditional and social media as well as the ways news organisations propose to manage their journalists' social media presence.

\section{SOCIAL MEDIA AND JOURNALISM}

Social media have become increasingly popular with the public since the mid2000s. Recent studies indicate that their use of for example Facebook and Twitter is widespread and increasing (Pew Research Center, 2015; Reuters Institute for the Study of Journalism, 2015). Such mass adoption was bound to attract journalists. Over the past few years, what has essentially become an entirely new online ecosystem - for many, the whole meaning of the Internet - 
has played a key journalistic role in a number of important events such as the London riots, the Sandy Hook shooting, the Arab Spring uprisings, the Charlie Hebdo murders, ISIS' terror propaganda campaign... . Take Twitter, for example. Since 2009 (the year the platform switched taglines from "What are you doing?" to "What's happening?") the service that began with a focus on daily chatter and ambient intimacy has morphed into an event-tracking platform (Rogers, 2014). This means more followers and more reporting being done through social media, drawing in ever higher numbers of readers and journalists.

A lot of research has been conducted into the usefulness of social media from a journalistic point of view - for instance, the way in which journalists use platforms such as Facebook and Twitter to research, break, distribute and discuss news (Bruns, 2012; Hermida 2010; Lasorsa, 2012; Vis, 2013) or as a tool for personal branding (Molyneux \& Holton, 2015). Hermida (2010) describes the role of social media in the development of ambient journalism, which is about immediately identifying trends and news by using social media platforms as awareness systems. Not only does the presence of journalists and media organisations on social media improve traffic to their online sites (Hong, 2012), it also makes the journalistic production process more transparent (Lasorsa, 2012).

\section{SOCIAL MEDIA AND THE DIGITAL SHIFT}

Based on the above we can conclude that today, social media and journalism are inextricably linked and that the new platforms can generate added value for 
news consumers and journalists alike. Several arguments exist why social media should not be considered an outright force for good, however.

British market research from 2012 has shown that journalists mostly worry about privacy issues, information unreliability and a lack of objectivity due to the high immediacy of the medium (Cision, 2012). Traditional (i.e. print, etc.) journalists take a dimmer view of social media than online journalists, and they are more concerned about potential disadvantages (Opgenhaffen, Corten \& d'Haenens 2011; Hedman \& Djerf-Pierre 2013). The same applies to news consumers. Recent research shows that social media are considered as the least reliable by news consumers, who highly distrust the information presented on these platforms compared to online and broadcast news-even in the under-35 age category (Reuters Institute for the Study of Journalism, 2015). In other words, both newsmakers and news consumers fear that social media can jeopardise the credibility and objectivity of the journalist and journalistic work.

It is a well-known fact that within the profession there is a fear that new technologies will affect the quality of journalistic work (e.g. Deuze, 2005; Pavlik, 2000). Ten years ago Singer (2005) studied the impact of social media on routines and principles among blogging journalists (the so-called J-bloggers). This study showed there was not much to worry about: while expression of personal opinions increased, blogging journalists stuck to their gatekeeping principles and mostly linked to articles on mainstream news sites. Then Lasorsa and colleagues (2012) studied the interaction of journalistic standards and principles with social media practices among journalists active on Twitter (the 
so-called J-tweeters), and vice versa. Based on an analysis of tweets posted by 500 journalists, the authors found that tweeting journalists voice a great many personal opinions via the platform, make the gatekeeping process public, and also provide greater transparency about their work. They concluded that journalists who use Twitter "appear to be normalizing microblogs to fit into their existing norms and practices but, at the same time, they appear to be adjusting these professional norms and practices to the evolving norms and practices of Twitter" (Lasorsa, Lewis \& Holton 2012: 13). The overall conclusion of this and other studies into the impact of new technologies and online/social media is that journalistic practices are indeed changing under the influence of new/social media. The mental context thus created, resulting for example in a change of opinion about the boundaries of 'social journalism', has different views on the importance of journalistic principles and routines, and has new insights into the relationship between news professionals and news consumers.

Such a mental paradigm shift is not always easy. For instance, Lewis (2012) states that traditional news organisations and newsmakers are suffering from a societal shift towards a more participatory and social form of journalism. This even (or perhaps mostly) applies to large news organisations. Recent ethnographic research at The New York Times demonstrated a very real clash of values as emerging values reorganise the news flow and routines. At the New York Times, many possibilities for new forms of engagement between the audience and the press are present, but at higher levels within the organisation, those platforms are mainly used for promotional purposes, while journalists are not keen to interact with their readers (Usher, 2014). Tameling (2015), who 
researched three major Dutch news outlets observed that both journalists and management struggle to define an online strategy. On the one hand they are confronted with a new digital reality, bringing with it lots of possibilities, on the other hand they cling on to traditional journalistic routines for as long as possible. Hence, for media company managers, the situation is far from simple: social media create opportunities in terms of content, interaction and promotion, but the risk of journalists harming the organisation's reputation - through a personal message on Facebook or by leaking a scoop on Twitter - inhibits change.

This duality is an illustration of the permanent presence of conflicting demands within media organisations, similar to the duality seen between art and commerce (Caves, 2001) or between product design and management (Underwood, 1993). Stated differently: "(...) the editors-in-chief are responsible for making the daily product, but not for the economic results of its circulation, and tensions between editorial and management staff often occur" (Achtenhagen \& Raviola, 2009). Specifically for social media, this can lead to management deciding that Facebook and Twitter are to be used primarily for branding and promotion, and less for new developments such as storytelling and curating (see e.g., Bloom, Cleary \& North, 2015; Hille \& Bakker, 2013). Similarly, conflicts may arise when management notices that journalists relax certain well-accepted journalistic standards and principles or adapt these to social media platforms, sometimes crossing the line, like the example at the beginning. Undeniably this gives rise to tensions within media organisations, something that management must answer for. That is no easy feat. Direct influence from management on the newsroom floor, for example to prohibit matters or set requirements, is seen as 
something difficult. After all, journalists tend to have more liberal attitudes and believe that autonomy is important (see e.g. Breed, 1955). At the same time journalists cannot decide how they should behave on social media independently of management. According to Schoemaker and Reese (2014), the organisation a journalist works for in large part determines the approach applied. At the organisational level management first determines how professionalism is defined, subsequently a number of values are developed to meet the organisation's needs. This can lead to tensions as "media organisations selectively promote certain aspects of professionalism, not all of which place a strong emphasis on individual freedom" (Schoemaker \& Reese, 2014: 10). In respect of these conflicts between management and editors, Achtenhagen and Raviola (2009) argue in contrast that within a media organisation facing a digital revolution, there is no need to choose a side in the conflict, as this is no longer appropriate given the dynamics of an ever-changing and complex media environment, but rather a simultaneous existence of conflicting results may be the objective, whereby it isn't necessary to resolve the tension as such, but to reduce the negative impact of the existing duality. This can be done for example by organising specific training for the parties involved and, more generally, by improving the communication between members of the media organisation (e.g. management and journalists) to address the conflict, at least perceptually.

To fill a clear research gap about how people within a media organisation treat the tension caused by social media, in this paper we elaborate on how social media guidelines are used strategically by the management of media 
organisations to communicate about what is or isn't allowed, in order to provide clarity and reduce the existing tension between editorial staff and management.

\section{SOCIAL MEDIA GUIDELINES}

Following from the above, we can conclude that social media are popular as a journalistic instrument, and that there are undeniable advantages linked to using them. At the same time, we cannot ignore social media's potential impact on common and widely accepted journalistic principles. Given that it has become increasingly commonplace in various other industries to manage employees' social media behaviour (Carim \& Warwick, 2013), organisations can develop social media guidelines to control the behaviour of their journalists. These guidelines can elaborate on the advantages of social media, for instance to motivate journalists to try and lure social media users to a news site or a traditional medium, to encourage journalists to interact with the public, conduct research and increase transparency. Also, guidelines may remind journalists of their profession's basic standards, and work to prevent social media from undermining any non-partisanship, gatekeeping, and discretion principles. They may explain why a homophobic tweet is unacceptable, for instance.

Based on the little available research into guidelines within media companies, we can only make tentative estimates of the number of companies that employ such guidelines. A small study of social media policies at seven international news organisations found that about half used a specific social media guideline (Bloom et al., 2015). This figure is in line with a study of Belgian news media 
(Opgenhaffen \& Scheerlinck, 2014). The latter study indicated that most journalists argue any guideline or directive made by the management is not really necessary and that common sense should be enough to avoid glaring mistakes on social media. In contrast, one-on-one interviews uncovered a broad variety of opinions. As far as expression of personal opinions is concerned, some suggested that this should absolutely be possible, while others were against it, especially in the case of political statements. The notion of social media guidelines on gatekeeping and transparency was met with equally diverse views. So while common sense may be a sufficient safeguard while using social media, no consensus among journalists exists. A number of journalists indicated that they regretted management did not provide guidelines because they were uncertain of what was or wasn't allowed on social media. Specific guidelines may therefore be useful for a news organisation to outline its journalists' social media presence - i.e., to make sure they are productive while avoiding online blunders.

This paper aims to determine the content of social media guidelines issued in recent years by a set of selected market-leading news media and press agencies. More specifically, we examine which aspects are included in the guidelines that can be linked to the prevailing journalistic practices.

\section{METHOD}

To answer the research question, we have analysed existing social media guidelines. As a general frame of reference guiding our analysis, we used 'sensitising concepts' (Blumler, 1954) derived from previous research into the 
relationship between social media and journalistic standards, i.e. gatekeeping, objectivity (or rather: non-partisanship) and transparency (see e.g., Lasorsa, 2012; Lasorsa et al., 2012; Lawrence et al., 2013; Lewis \& Usher, 2013; Singer, 2005). Subsequently we analysed the content of the social media guidelines using open, axial, and selective coding in order to develop more specific trends in clusters of guidelines. Only the formulations which were explicitly included in the guidelines were included in the analysis. In our reporting we have attempted to map out the guidelines by assigning their provisions to various categories. The findings in our tables ( 1 to 3 ) do not always include the guidelines' actual wording. We often used a descriptive summary that applies to all the guidelines in a specific category. There were only a few guidelines that we were unable to assign to one specific category. Such guidelines were included twice.

We combined various approaches to research existing social media guidelines issued by market-leading news media. First, we checked if any such documents were available online. A simple googling session resulted in the guidelines of various news media and press agencies. We also sent e-mails to various organisations asking them to provide us their guidelines, which resulted in two additional entries (only two answered). A personal contact forwarded us the guidelines of an organisation that had not replied to our e-mail and whose rules and regulations were not available online. As a result, our set, consisting of scattered, non-static material is far from complete but can serve as a start. We analysed a total of 12 sets of guidelines, ranging from a one-page informal document with 8 general provisions to a full chapter in a manual. The news agencies, public and commercial broadcasters, cross media organisations and 
newspapers studied are all market leaders in their industry: Reuters (UK/USA), AP (USA), BBC (UK), HLN (Belgium), AFP (France), VRT (Belgium), Mediahuis (Belgium), Sky News (UK), CBC radio (Canada), The Guardian (UK), The Washington Post (USA), and ABC (Australia). These guidelines were collected in the spring of 2014 .

\section{RESULTS}

\section{Personal use}

The first group of guidelines we identified included rules, tips, and advice related to the basic principle of non-partisanship in journalism: to remain neutral (nonpartisan) at all times and refrain from advancing one's personal agenda. Our analysis identified several provisions that pertain to this. Table 1 lists the various rules within these two sub-dimensions, linking them with the organisation they originate from. In this group we were able to single out two types of provisions.

TABLE 1 AROUND HERE

The first group sets out duties or limitations that are explicitly linked to an account or a profile. These include compulsory use of one's real name when creating an account, prohibition of any personal information sharing through one's professional account, an obligation to clearly state whether one is speaking 
in one's own name ("views are my own" statements) or on behalf of one's employer, and suggestions concerning privacy settings, the idea being that not everybody should be able to view one's profile or status updates (e.g. on Facebook). What immediately stands out is that there are differing ideas about the use of a professional vs. a private account. Some news organisations (ABC, $\mathrm{BBC}, \mathrm{AFP}$, Reuters) require journalists to clearly differentiate their personal online persona from their professional one, while another (AP) requires the use of one single account for both private and professional purposes. Sky News forbids its employees from tweeting about personal opinions on their professional account. Somewhat less stringent and less constraining than the latter is the provision by Mediahuis, $\mathrm{ABC}, \mathrm{BBC}$, Washington Post, $\mathrm{AFP}$ and Reuters that a journalist must always clearly state whether she/he is speaking in her/his own name or on behalf of the organisation. In other words: different views about how to manage the (formal) use of personal vs. professional accounts/profiles as a news organisation exist.

A second group of guidelines about non-partisanship relates to message content on social media. Some guidelines explicitly state that a journalist must not express personal opinions on controversial topics, nor insult or criticize anyone, including one's colleagues (VRT, Washington Post, Reuters, AP and AFP). In light of the tweet mentioned at the beginning of this article, the following provision from VRT's guideline is quite interesting: 
Humour is allowed on social media. But you should avoid insulting or hurting people. Do not lash out at colleagues. Not even colleagues from other media. (VRT, 2012)

Several organisations stipulate that journalists should think carefully about the way their posts will reflect on their employer. In other words, when a journalist plans to post a tweet or a Facebook status update, she/he must take into account the positive or, mainly, negative impact the text, photo or video may have on the organisation's image. The BBC is even stricter, requiring journalists to have all posts vetted before publication. The most common provision in this subcategory, however, is that whatever the subject, political or otherwise, a journalist must strive to remain objective (Mediahuis, $\mathrm{BBC}, \mathrm{CBC}$, $\mathrm{AP}$, etc.). The Guardian asks journalists to declare personal interest when applicable.

\section{Gatekeeping}

Various news organisations are aware that they can benefit from involving citizens in the news process. Indeed, several specific provisions explicitly discuss the relationship between journalists and the public. We can classify these provisions into two sub-dimensions (see table 2). First, we noticed several rules about 'stage sharing' (Lasorsa et al., 2012) - that is, involving the public more in the journalistic research and production process. Journalists are expected to encourage the public to interact and contribute news, and to reward them when they do. The Guardian, The Washington Post and AP all have guidelines to this effect. Other organisations tend to focus on the added value of a large network 
(AP) or the search for eyewitnesses through crowdsourcing (VRT). Others encourage journalists to have an online presence (ABC, AP, AFP and Reuters).

It is important to note that only a few provisions caution about stage sharing, or explicitly prohibit specific actions such as tweeting information from an outside source (SKY) or straight retweeting (AP), out of fear that the journalist may seem to endorse what may have come from a non-professional source.

TABLE 2 AROUND HERE

A second set of provisions pertains to the way a journalist should deal with information provided by regular users or uncovered through social media. HLN (the leader in the small newspaper market) is especially vocal about this: its guidelines state that one may not violate people's privacy and must be highly cautious with respect to people in vulnerable situations, such as seriously injured (or dead) people, including when taking photos. It is worth noting that HLN adopted this guideline following the Flemish Press Council, which issued this position in reaction to the Sierre coach crash (March 13, 2012) in which 28 people got killed, 22 of them children whose Facebook pictures were printed in two newspapers, including HLN. This explains the emphasis on ethically correct and deliberate use of sources' personal data. 


\section{Transparency}

Regarding transparency guidelines, our analysis identified four distinct types (see table 3). The first type includes the general rule that a journalist should behave in a completely open manner, and/or states specifically that any post must include links to its sources. Four of the organisations studied have adopted the first rule, five the second. The danger of total transparency is of course disclosure of secret or sensitive information. Various news media anticipate this by employing guidelines that require journalists to behave with discretion, prohibiting them from disseminating confidential information, criticising colleagues or internal operations, etc. One guideline (AP) explicitly forbids disseminating information that can endanger someone (e.g. discussing a topic which a colleague has been working on).

\section{TABLE 3 AROUND HERE}

As mentioned in the literature review, we can also consider the approach to scoops as a form of transparency. Table 3 clearly shows that many media organisations have formulated guidelines about scoops-all of them restrictive. Journalists may not tweet news of which their newsroom is unaware, nor may they announce breaking news. AP does allow 'live tweeting' (posting non-stop during an event). Notwithstanding, news media are also worried about the impact of social media on the accuracy of reporting. We found four different 
rules that explicitly pertain to information checking. These tell journalists to always check the truthfulness of sources before releasing any information, and also to correct any erroneous information that may have been disseminated. Moreover, the latter can be considered a form of transparent behaviour provided the journalist explicitly states the new post is meant to rectify a previous one.

\section{CONCLUSION / DISCUSSION}

The purpose of this study was to explore how social media guidelines take into account common journalistic standards that are possibly pressured by the use of Facebook, Twitter and similar platforms. The main conclusion of this paper is that a variety of guidelines exist which advise editors about non-partisanship, gatekeeping and transparency. News organisations have different opinions on how to ensure correct use of social media by their journalists from the perspective of the organisation. This is clearly the case for example within the personal use category. In other words, there is no homogeneity among the guidelines. Based on the available literature we know that developments in the field of social (and, by extension, digital and online) media create a certain tension within media organisations. Media guidelines can be seen as an instrument to introduce clarity on what management thinks is allowed or not, or what is encouraged or explicitly prohibited. Precisely because it is used as a tool for clarification, it does not seem unreasonable that guidelines are aligned with whatever management supports but also take into account the editorial culture and the current use of social media by the organisation's journalists. We know based on literature that news makers themselves disagree about what is and is 
not acceptable in terms of expression of personal opinion, 'stage sharing' and scoops. Because we have examined guidelines of media companies which differ in terms of organisation size, media type, activity, corporate culture, country, etc., it is perfectly understandable that this gives rise to a wide variety of guidelines in the study.

Following from this we can argue that it would not be appropriate from a media management perspective to develop a universal, uniform guideline which can be deployed worldwide by several media organisations. Media organisations which are on the verge of drawing up a separate guideline may however be inspired by the multitude of recommendations from this study. Future research - including a much larger sample than in the current study to ensure external validity - should focus on the differences between the various types of media organisations and the corresponding differences in their social media guidelines. Ethnographic research within media organisations can in turn identify how the guidelines come about, and more specifically how management arrives at the specific formulations (e.g. incentive vs. restrictive) and to what extent whatever is going on the editorial floor is taken into account.

Another important finding of this study is that a lot of formulations exist concerning the involvement of the public in the production process and ensuring transparent journalism. Hence we identified opinions related to encouraging journalists to take part in online discussions and the call to link to sources while discussing on social media. Based on the above we can argue - albeit with caution because of the small sample - that media organisations seem to realize they 
stand to benefit from a measure of 'gate opening' and that the general idea of an 'ethic of participation' (Lewis, 2012) between news professionals and the public is embedded in existing social media guidelines. The question is of course what the main reason is to include these types of directives: does it stem from a genuine awareness that external stakeholders are important and are entitled to transparency and responsiveness of the journalists, or maybe because it is assumed that transparency and interactivity is positive for the media brand's reputation and may have a positive impact on the quality of journalism? Answering this question is beyond the scoop of this article, but the fact that only a few media companies have included explicit advice on safeguarding sources makes us suspect that the organisations mainly use a medium-centred approach rather than a user-centred approach when determining the content of the guidelines. In-depth research including observations at multiple media companies and interviews with the persons responsible for the content of the guidelines should provide more insight in this area in the future.

An important remark here is that we should take into account the fact that any lack of specific provisions on a given topic does not mean that the news organisation ignores that topic. It may be that some principles are at play, which are so obvious or generally accepted by all that they do not need to be articulated in a guideline or directive. Moreover, media organisations may work based on a general set of house rules that naturally apply to social media as well. The Guardian's social media guidelines for example explicitly refer to a general community standard that covers all aspects of interaction and moderation on its website (including comments on blogs or article pages), capturing all aspects of 
social media. This also comes up in one of the studies previously discussed (Bloom et al., 2015). Future research may focus on the analysis of the similarities and differences between general editorial and social media-specific guidelines.

This paper has presented links between social media guidelines and the basic journalistic tenets that are being challenged by the rise of social media. We are convinced that mapping the existing diversity of recommendations and restrictions provides relevant insights for media management and journalism studies scholars. Such insights are needed to better understand the use of social media by journalists and the implementation of guidelines on this subject by media organisations. More practically, this summary and the accompanying observations can aid media organisations who are shaping their own set of rules regarding use of social media by their staff.

\section{REFERENCES}

Achtenhagen, L., \& Raviola, E. (2009). Balancing Tensions During Convergence: Duality Management in a Newspaper Company. The International Journal on Media Management, 11, 32-41.

Bloom, T., Cleary J., \& North, M. (2015). Traversing the "Twittersphere". Social media policies in international news operations. Journalism Practice (published online on March 2015).

Blumer, H. (1954). What is Wrong with Social Theory? American Sociological Review, 19, 3-10.

Breed, W. (1955). Social Control in the Newsroom: A Functional Analysis. Social Forces, 33(4), 326-35.

Bruns, A. (2012). Journalists and Twitter: How Australian News Organisations Adapt to a New Medium. Media International Australia incorporating Culture and Policy, 144, 97-107.

Carim, L., \& Warwick, C. (2013). Use of social media for corporate communications by research-funding organisations in the UK. Public Relations 
Review, 39, 521-525.

Caves, R. E. (2001). Creative industries: Contracts between arts and commerce. Cambridge, MA: Harvard University Press.

Cision. 2012. Social Journalism: Full story. Retrieved June 22, 2013, from Http://www.cision.com/uk/files/2012/09/Social-Journalism-Study-FullReport.pdf

Deuze, M. (2005). What Is Journalism? Professional Identity and Ideology of Journalists Reconsidered. Journalism, 6, 442-464.

Hedman, U., \& Djerf-Pierre, M. (2013). The Social Journalist: Embracing the Social Media Life or Creating a New Digital Divide? Digital Journalism, 1, 368-385.

Hermida, A. (2010). Twittering the News: The Emergence of Ambient Journalism. Journalism Practice, 4, 297-308.

Hille, S., \& Bakker, P. (2013). I like news. Searching for the 'Holy Grail' of social media: The use of Facebook by Dutch news media and their audiences. European Journal of Communication, 28, 663-680.

Hong, S. (2012). Online news on Twitter: Newspapers' Social Media Adoption and Their Online Readership. Information Economics and Policy, 24, 69-74.

Lasorsa, D. (2012). Transparency and Other Journalistic Norms on Twitter. Journalism Studies, 13, 402-417.

Lasorsa, D., Lewis, S. C., \& Holton, A. E. (2012). Normalizing Twitter: Journalism Practice in An Emerging Communication Space. Journalism Studies, 13, 19-36.

Lawrence, R. G., Molyneux, L., Coddington, M., \& Holton, A. (2013). Tweeting Conventions: Political journalists' use of Twitter to cover the 2012 presidential campaign. Journalism Studies, 15(6), 789-806.

Lewis, S. C. 2012. The Tension between Professional Control and Open Participation: Journalism and Its Boundaries. Information, communication \& Society, 15, 836-866.

Lewis, S. C., \& Usher, N. (2013). Open source and journalism: toward new frameworks for imagining news innovation. Media, Culture \& Society, 35(5), 60219.

Molyneux, L., \& Holton, A. (2014). Branding (Health) Journalism: Perceptions, practices, and emerging norms. Digital Journalism, 3(2), 225-242.

Opgenhaffen, M., Scheerlinck, H. (2014). Social media guidelines for journalists: An investigation into the sense and nonsense among Flemish journalists. Journalism Practice, 8, 726-741 
Opgenhaffen, M., Corten, M., \& d'Haenens, L. (2011). Nieuwsvaardig: een crossmediale competentiematrix voor journalisten [Newsable: a cross-media competency matrix for journalists]. Leuven: Lannoo Campus.

Pavlik, J. (2000). The Impact of Technology on Journalism. Journalism Studies, 1(2), 229-237.

Pew Research Center (2015). The Evolving Role of News on Twitter and Facebook. Retrieved August 23, 2015, from http://www.journalism.org/ files/2015/07/Twitter-and-News-Survey-Report-FINAL2.pdf

Reuters Institute for the Study of Journalism (2015). Reuters Institute Digital News Report 2015: Tracking the Future of News. Oxford: University of Oxford.

Rogers, R. (2014). Debanalising Twitter. The transformation of an Object of Study. In: K. Weller, A. Bruns, J. Burgess, M. Mahrt \& C. Puschmann (Eds.), Twitter and society (pp. ix-xxvi). New York: Peter Lang.

Shoemaker, P. J., \& Reese, S. D. (1996). Mediating the message: Theories of influences on mass media content. White Plains, NY: Longman.

Singer, J. (2005). The Political J-blogger: 'Normalizing' a New Media Form to Fit Old Norms and Practices. Journalism, 6, 173-198.

Tameling, K. (2015). En wat doen we online? Crossmediale dilemma's op de Nederlandse nieuwsredactie [What's happening online? Cross-media dilemmas in Dutch newsrooms]. Groningen: Rijksuniversiteit Groningen.

Underwood, D. (1993). When MBAs rule the newsroom. New York: Columbia University Press.

Usher, N. (2014). Making news at the New York Times. Ann Arbor: The University of Michigan Press.

Vis, F. (2013). Twitter as a Reporting Tool for Breaking News: Journalists Tweeting the 2011 UK Riots. Digital Journalism, 1, 27-47. 
Table 1. Social media guidelines about personal use

\begin{tabular}{|c|c|c|c|c|c|c|c|c|c|c|c|c|}
\hline & HLN & VRT & MH & $\mathrm{ABC}$ & BBC & $\mathrm{CBC}$ & GU & WP & AP & AFP & REU & SKY \\
\hline \multicolumn{13}{|l|}{ ACCOUNT } \\
\hline $\begin{array}{l}\text { Compulsory notification to organisation of a personal } \\
\text { account }\end{array}$ & & & & & & & & & $\sqrt{ }$ & & & \\
\hline $\begin{array}{l}\text { No mention that one is a journalist for a news organisation } \\
\text { on one's personal account }\end{array}$ & & & & & $\sqrt{ }$ & & & & & $\sqrt{ }$ & & \\
\hline Use of real name on social media & & & & & & & & & & $\sqrt{ }$ & & \\
\hline Mandatory mention of Twitter URL in profile & & & & & & & & & & $\sqrt{ }$ & & \\
\hline List your employer and job in your profile & & & & & & & & $\sqrt{ }$ & & $\sqrt{ }$ & $\sqrt{ }$ & \\
\hline State that you work for the organisation & & & & & & & & & $\sqrt{ }$ & & & \\
\hline $\begin{array}{l}\text { Clarify whether you are posting in your own name of on } \\
\text { behalf of your organisation }\end{array}$ & & & $\sqrt{ }$ & $\sqrt{ }$ & $\sqrt{ }$ & & & $\sqrt{ }$ & & $\sqrt{ }$ & $\sqrt{ }$ & \\
\hline $\begin{array}{l}\text { Distinguish between personal and professional } \\
\text { use/account }\end{array}$ & & & & $\sqrt{ }$ & $\sqrt{ }$ & & & & & $\sqrt{ }$ & $\sqrt{ }$ & \\
\hline Use one account for personal and professional purposes & & & & & & & & & $\sqrt{ }$ & & & \\
\hline Never post personal tweets to your professional account & & & & & & & & & & & & $\sqrt{ }$ \\
\hline No private use of social media during working hours & & & & $\sqrt{ }$ & & & & & & & $\sqrt{ }$ & \\
\hline Change your privacy and profile settings & & & $\sqrt{ }$ & & & & & & $\sqrt{ }$ & & & \\
\hline Keep a closed and limited circle of friends & & & & & & & & & $\sqrt{ }$ & $\sqrt{ }$ & & \\
\hline CONTENT & & & & & & & & & & & & \\
\hline Maintain political and common objectivity & & $\sqrt{ }$ & $\sqrt{ }$ & & $\sqrt{ }$ & $\sqrt{ }$ & & $\sqrt{ }$ & $\sqrt{ }$ & $\sqrt{ }$ & & \\
\hline Be careful about blurring fact and opinion & & & & & & & $\sqrt{ }$ & & & & & \\
\hline Declare personal interest when applicable & & & & & & & $\sqrt{ }$ & & & & & \\
\hline No expression of personal opinion on controversial topics & & & & & & $\sqrt{ }$ & & & $\sqrt{ }$ & & & \\
\hline Do not discredit the organisation & & & $\sqrt{ }$ & $\sqrt{ }$ & $\sqrt{ }$ & $\sqrt{ }$ & & & & & & \\
\hline Be aware that you represent an organisation & & & & & $\sqrt{ }$ & & & $\sqrt{ }$ & & & & \\
\hline $\begin{array}{l}\text { Do not offend people, do not criticise colleagues or other } \\
\text { people }\end{array}$ & & $\sqrt{ }$ & & & & & & $\sqrt{ }$ & $\sqrt{ }$ & $\sqrt{ }$ & $\sqrt{ }$ & \\
\hline No straight retweet & & & & & & & & & $\sqrt{ }$ & & & \\
\hline Always check the truthfulness of sources before posting & $\sqrt{ }$ & & & & & $\sqrt{ }$ & & & $\sqrt{ }$ & & & \\
\hline
\end{tabular}


Table 2. Social media guidelines about gatekeeping

\begin{tabular}{|c|c|c|c|c|c|c|c|c|c|c|c|c|}
\hline & HLN & VRT & $\mathrm{MH}$ & $\mathrm{ABC}$ & BBC & $\mathrm{CBC}$ & GU & WP & AP & AFP & REU & SKY \\
\hline \multicolumn{13}{|l|}{ SHARING THE STAGE } \\
\hline Extend your network through social media & & & & & & & & & $\sqrt{ }$ & & & \\
\hline Possibility to call on witnesses after consultation & & $\sqrt{ }$ & & & & & & & & & & \\
\hline Encourage the public to take part in the news process & & & & & & & $\sqrt{ }$ & $\sqrt{ }$ & $\sqrt{ }$ & & & \\
\hline $\begin{array}{l}\text { Be encouraged as a journalist to participate in online } \\
\text { debate }\end{array}$ & & & & $\sqrt{ }$ & & & & & $\sqrt{ }$ & $\sqrt{ }$ & $\sqrt{ }$ & \\
\hline Reward people who supply news & & & & & & & $\sqrt{ }$ & $\sqrt{ }$ & & & & \\
\hline Do not delete comments if you do not agree & & & & & & & & & & & $\sqrt{ }$ & \\
\hline No straight retweet & & & & & & & & & $\sqrt{ }$ & & & \\
\hline Avoid endless discussions on social media & & $\sqrt{ }$ & & & & & & & & & & \\
\hline Only retweet sources after checking the information & & $\sqrt{ }$ & & & & & & & & & & \\
\hline $\begin{array}{l}\text { Never tweet information from someone outside of the } \\
\text { organisation }\end{array}$ & & & & & & & & & & & & $\sqrt{ }$ \\
\hline SAFEGUARDING SOURCES & & & & & & & & & & & & \\
\hline No privacy violation & $\sqrt{ }$ & & & & & & & & & & & \\
\hline $\begin{array}{l}\text { Do not use any photos unless news relevance takes } \\
\text { precedence over privacy }\end{array}$ & $\sqrt{ }$ & & & & & & & & & & & \\
\hline $\begin{array}{l}\text { Use caution with respect to people in vulnerable positions } \\
\text { seriously injured (or dead) individuals }\end{array}$ & $\sqrt{ }$ & & & & & & & & & & & \\
\hline Information can be collected online, subject to consent & $\sqrt{ }$ & & & & & & & & & & & \\
\hline Do not publish recognisable photos without consultation & & $\sqrt{ }$ & & & & & & & & & & \\
\hline Always respect copyright & & & & & & & & & & & $\sqrt{ }$ & \\
\hline
\end{tabular}


Table 3. Social media guidelines about transparency

\begin{tabular}{|c|c|c|c|c|c|c|c|c|c|c|c|c|}
\hline & HLN & VRT & $\mathrm{MH}$ & $\mathrm{ABC}$ & BBC & $\mathrm{CBC}$ & GU & WP & $\mathrm{AP}$ & AFP & REU & SKY \\
\hline \multicolumn{13}{|l|}{ TRANSPARENCY } \\
\hline Be transparent and clear & & & & & $\sqrt{ }$ & & $\sqrt{ }$ & $\sqrt{ }$ & & & $\sqrt{ }$ & \\
\hline Link to sources you are discussing or to own content & & & & & $\sqrt{ }$ & & $\sqrt{ }$ & $\sqrt{ }$ & $\sqrt{ }$ & $\sqrt{ }$ & & \\
\hline \multicolumn{13}{|l|}{ DISCRETION } \\
\hline Do not disseminate confidential information & & $\sqrt{ }$ & $\sqrt{ }$ & $\sqrt{ }$ & $\sqrt{ }$ & & & & $\sqrt{ }$ & $\sqrt{ }$ & $\sqrt{ }$ & \\
\hline $\begin{array}{l}\text { Do not offend people, do not criticise colleagues or other } \\
\text { people }\end{array}$ & & $\sqrt{ }$ & & & & & & $\sqrt{ }$ & $\sqrt{ }$ & $\sqrt{ }$ & $\sqrt{ }$ & \\
\hline Do not criticise any aspect of your own organisation & & & $\sqrt{ }$ & & & & & $\sqrt{ }$ & & & & \\
\hline Do not endanger colleagues & & & & & & & & & $\sqrt{ }$ & & & \\
\hline \multicolumn{13}{|l|}{ SCOOPS } \\
\hline Live tweeting possible & & & & & & & & & $\sqrt{ }$ & & & \\
\hline Do not tweet news that the newsroom was not aware of & & $\sqrt{ }$ & & & & & & & & $\sqrt{ }$ & & \\
\hline Dot not break news & & & & & & & & & & $\sqrt{ }$ & & \\
\hline Always notify the newsroom of breaking news & & & & & & & & & & & & $\sqrt{ }$ \\
\hline \multicolumn{13}{|l|}{ ACCURACY } \\
\hline Always check the veracity of sources before posting & & $\sqrt{ }$ & & & & $\sqrt{ }$ & & & $\sqrt{ }$ & & & \\
\hline Check online sources in the same way as offline sources & & & & & & & & $\sqrt{ }$ & $\sqrt{ }$ & & & \\
\hline Rectify incorrect news posts & & & & & $\sqrt{ }$ & & & & & $\sqrt{ }$ & & \\
\hline Only retweet sources after checking their veracity & & $\sqrt{ }$ & & & & & & & & & & \\
\hline
\end{tabular}

